\title{
Optimising a solvent system for lipid extraction from cyanobacterium Microcystis spp.: future perspective for biodiesel production
}

\author{
D.A.T. Madusanka and Pathmalal M. Manage * \\ Centre for Water Quality and Algae Research, Department of Zoology, Faculty of Applied Sciences, University of Sri Jayewardenepura, \\ Gangodawila, Nugegoda.
}

\begin{abstract}
Due to unsustainability of petro derived fuels, the world is now concerned about alternative, sustainable and eco-friendly energy production. As a successful alternative energy, biodiesel plays a major role to replace petrodiesel. Cyanobacterial lipids have great potential for biodiesel production due to their rapid growth rate and renewability. The production of biodiesel from biomasses depends on upstream (lipid extraction) and downstream (trans-esterification) processes. Lipid extraction should be effective and energy efficient to reduce the production cost of commercial biodiesel production. Therefore, the present study was experimented to optimise the lipid extraction solvent system from cyanobacteria.

Cyanobacteria samples were collected from Beira Lake, Colombo where, Microcystis spp. are dominant ( $>96 \%)$. Solvent systems n-hexane, chloroform: methanol (2:1), n-hexane: ethanol (3:2), chloroform: n-hexane (1:1), dichloromethane: methanol (1:1), n-hexane: isopropanol (2:3) and diethyl ether were used for lipid extraction and subjected to optimisation for the lipid extraction method from the cyanobacterium Microcystis spp. Extracted lipid yield (g/1 g of dried biomass) for each solvent system was 1.11 wt. $\%, 1.61 \mathrm{wt} \%, 1.71 \mathrm{wt} . \%$, 2.15 wt. $\%, 3.41$ wt. $\%, 4.33$ wt. $\%$ and 1.95 wt. $\%$, respectively where fatty acid methyl ester (FAME) compositions found to be $80.13 \%, 78.27 \%, 76.39 \%, 29.01 \%, 85.72 \%, 92.39 \%$ and $80.09 \%$ in each system. The gas chromatographic-mass spectrometry analysis of the products revealed that the most abundant fatty acid types of Microcystis spp. were palmitic acid (C16:0) and its derivative such as 14-methyl pentadecanoic acid. The highest lipid yield (4.33 wt. \%) and fatty acid methyl ester $(92.39 \%)$ composition were recorded from n-hexane: isopropanol solvent system.
\end{abstract}

Keywords: Fatty acid methyl esters, lipid extraction solvent systems, Microcystis spp.

\section{INTRODUCTION}

Fossil fuels are the major energy sources throughout the world. According to the calculation given by Shafiee and Topal (2008), fossil fuel reserves of oil, natural gas and coal will deplete within approximately 35, 37 and 107 years, respectively. Among many alternative energy sources such as solar energy, tidal energy and hydro-power, biofuels play a major role and may give a potential solution for future energy crisis sustainably.

Biofuels are carbon neutral and will not result in a net release of carbon dioxide gas to the atmosphere. Out of many biofuel types, biodiesel is the most important type that is a promising alternative to fossil fuel for compression-ignition (CI) engines (Huang et al., 2012). Biofuels derived from microalgae and cyanobacteria belong to the third generation biofuel type (Daroch et al., 2013). Thus, biodiesel from microalgae or cyanobacteria is a novel concept, which is popular among the scientific community. Cyanobacteria commonly called as blue green algae have simple cellular structures (Da Rós et al., 2012) and they are microscopic photosynthetic organisms found in both marine and freshwater environments (Brennan \& Owende, 2010). Unlike microalgae, cyanobacteria are the dominant phytoplankton group in

*Corresponding author (pathmalal@sjp.ac.lk; (D https://orcid.org/0000-0002-2014-2060)

This article is published under the Creative Commons CC-BY-ND License (http://creativecommons.org/licenses/by-nd/4.0/). This license permits use, distribution and reproduction, commercial and non-commercial, provided that the original work is properly cited and is not changed anyway. 
eutrophic freshwater bodies where water is polluted by nitrogen and phosphorus (Sethunge \& Manage, 2013). They are prokaryotes, possessing a cell wall composed of peptidoglycan and lipopolysaccharide layers instead of the cellulose of green algae (Da Rós et al., 2012).

Cyanobacteria are mainly sunlight driven organisms and contain lipids, proteins and many other bioactive compounds such as pigments, carotenoids, ketones etc. (Da Rós et al., 2012). Out of these, lipids are considered as the responsible component for production of biodiesel (Huang et al., 2010; Da Rós et al., 2012; Mubarak et al., 2014). Cyanobacterial lipids mostly range within 12 - 22 carbon atoms and the lipid molecules can be either saturated or unsaturated (Huang et al., 2010; Mubarak et al., 2014). Based on the polarity of the lipid head group, lipids can be categorised into neutral or polar lipids (Halim et al., 2012).

Due to high photosynthetic efficiency, high biomass production, rapid lipid accumulation (Halim et al., 2012) and fast growth rate than other conventional crop products, oil rich cyanobacteria are considered as a good source of carbon neutral biodiesel production (Miao \& Wu, 2006; Huang et al., 2010). Depending on the species, conditions and other parameters, cyanobacteria produce many different kinds of lipids, hydrocarbons and other complex oils (Metzger \& Largeau, 2005; Guschina \& Harwood, 2006; Huang et al., 2010). All algal oils are not satisfactory for the production of biodiesel, but neutral fatty acids such as palmitic acids are desirable for biodiesel production (Chisti, 2007; Da Rós et al., 2012).

Most of the recreational freshwater bodies in Sri Lanka are being eutrophicated and the genus Microcystis is the dominant and well distributed cyanobacterium (Sethunga \& Manage, 2013). In the Beira Lake, M. aeruginosa is the dominant cyanobacteria species where $M$. wesenbergii and $M$. incerta are co-dominant species. Idroos et al. (2014) recorded that Microcystis spp. increase their biomass more than $95 \%$ in the Beira Lake throughout the year.

According to Huang et al. (2010) the production cost is generally high for biodiesel, and the cost of raw materials (fat or oil) and downstream processing (transesterification) can be considered as two main components of the production cost of biodiesel. Therefore, an efficient solvent system for lipid extraction from cyanobacteria is more important to chemical based upstream processes in commercial biodiesel production to reduce the production cost. Thus, the present study was carried out to optimise an efficient solvent system for lipid extraction from Microcystis spp.

\section{METHODOLOGY}

\section{Sampling}

Microcystis bloom samples were collected from the Beira Lake from March to August in 3 sampling occasions, and $100 \mathrm{~L}$ of bloom samples were collected into plastic containers and transported to the laboratory.

\section{Harvesting and extraction pre-treatments}

Bloom samples were filtered through a $1 \mathrm{~mm}^{2}$ wire mesh to remove debris and were concentrated using the electrolytic foam floating (EFF) apparatus. Approximately $10-12 \mathrm{~h}$ was taken for the concentration process of $20 \mathrm{~L}$ of bloom sample through the EFF apparatus.

The concentrated bloom samples were dried under sunlight for 3-4 d until complete removal of water. After drying, the biomass was subjected to fine grinding using a mortar and pestle. Then the powdered biomass was stored under cold conditions $\left(5^{\circ} \mathrm{C}\right)$ until lipid extraction was performed (Halim et al., 2011).

\section{Lipid extraction from cyanobacteria}

Lipid extraction was carried out using 7 different solvent systems of n-hexane, chloroform: methanol (1:2), n-hexane: chloroform (1:1), dichloromethane (DCM): methanol (1:1), isopropanol: n-hexane (3:2) and diethyl ether to assess the lipid content of the Microcystis biomass.

Dried Microcystis powder (20.00 g) was weighed and placed in the round bottom flask of the soxhlet apparatus at $80{ }^{\circ} \mathrm{C}$, and $100 \mathrm{~mL}$ of solvent was added in order to get Microcystis dry biomass: solvent in 1:5 (W/V) ratio (Fajardo et al., 2007). Extraction was carried out for $10 \mathrm{hrs}$ and the procedure was repeated 3 times for each solvent system. After that, the mixture was re-dissolved in each solvent system for lipid extraction. The dissolved lipid fraction was subjected to washing with water in order to remove contaminants such as pigments and nonlipid contaminants. The washing process was continued until the lipid dissolved organic layer becomes clear. Then, the purified lipid product was subjected to drying process using the rotary evaporator (Halim et al., 2011). Dried lipids were mixed with $20 \mathrm{~mL}$ of n-hexane and stored at $5{ }^{\circ} \mathrm{C}$ to reduce the chemical and photo oxidation reaction (Halim et al., 2011). 


\section{Lipid trans-esterification}

Trans-esterification processes of lipid fractions were done by a modified method of the fatty acid methylation procedure given in Halim et al. (2011). The dried lipid was re-dissolved in $20 \mathrm{~mL}$ of hexane in order to enhance the reaction kinetics during trans-esterification. Roughly 1:5 volume ratio of cyanobacterial oil to methanol was added. As lipids and methanol are not miscible (Moser, 2009), a two-step protocol was used for the methylation process of all the extracted lipids, and all the reagents were added in stoichiometric excess (Halim et al., 2011). In the first step $\mathrm{H}_{2} \mathrm{SO}_{4}$ was used as the acid catalyst for methylation of free fatty acids (FFAs) and in the second step potassium methoxide $\left(\mathrm{KCH}_{3} \mathrm{O}\right)$ was used as the base catalyst to methylate the acylglycerols. Five milliliters of conc. $\mathrm{H}_{2} \mathrm{SO}_{4}$ was added to the lipid methanol mixture and heated at $50^{\circ} \mathrm{C}$ with moderate agitation for $2 \mathrm{~h}$. During the period, the evaporated methanol was replenished. Then 25 wt. $\% \mathrm{KCH}_{3} \mathrm{O}$ solution was prepared by dissolving $25.00 \mathrm{~g}$ of $\mathrm{KCH}_{3} \mathrm{O}$ in $127 \mathrm{~mL}$ of methanol and added dropwise to the gently stirred lipid methanol mixture until $\mathrm{pH} 12$ was attained. The mixture was heated at $55{ }^{\circ} \mathrm{C}$ and moderately agitated for $2 \mathrm{~h}$, and evaporated methanol was frequently replenished.

After trans-esterification was completed, transesterified fatty acids were re-dissolved in n-hexane. Then the dissolved fatty acid methyl esters (FAMEs) were washed with water to remove methylation by-products, methanol, remaining catalysts, etc.

\section{GCMS screening of FAMEs}

Two hundred micro liters of pure FAME was dissolved in $800 \mu \mathrm{L}$ of $\mathrm{n}$-hexane prior to gas chromatographicmass spectrometry (GCMS) screening. The FAME composition was analysed by GCMS, Agilent USA model 7890 GC with Agilent 19091S-433HP-5MS capillary column $(30 \mathrm{~m} \times 250 \mu \mathrm{m} \times 0.25 \mu \mathrm{m})$.

Two microliters of sample was injected in split mode with 100:1 split ratio and split-flow in $50 \mathrm{mLmin}^{-1}$. The initial oven temperature was maintained at $160{ }^{\circ} \mathrm{C}$ for $10 \mathrm{~min}$, and then the temperature was ramped to $190{ }^{\circ} \mathrm{C}$ for 5 min with $3{ }^{\circ} \mathrm{Cmin}^{-1}$ rate. Finally, the oven temperature was raised to $280{ }^{\circ} \mathrm{C}$ with $10{ }^{\circ} \mathrm{Cmin}^{-1}$ rate and the temperature was maintained for $14 \mathrm{~min}$. Helium $(\mathrm{He})$ was used as the carrier gas and total run time was $45 \mathrm{~min}$.

\section{Optimising a solvent system}

Lipid yields, volume of FAME products, relative percentage of total FAME and relative percentage of saturated and unsaturated FAME of different solvent systems were the major criteria for optimisation. Properties of the most available methyl esters, such as carbon chain length, chain structure and saturation or unsaturation of the FAME molecule of all solvent systems were assessed to select the most appropriate solvent system for further experiments.

\section{RESULTS AND DISCUSSION}

In the present study, the highest lipid yield (4.33 wt. \%) was recorded from $n$-hexane: isopropanol solvent system, whereas the lowest lipid yield (1.11 wt. \%) was recorded from the n-hexane solvent system (Figure 1). The second highest lipid yield was recorded from DCM: methanol solvent system, which was 3.14 wt. \%. In the present study lipid yield varied from 1.1 wt. \% to 4.33 wt. \% (Figure 1).

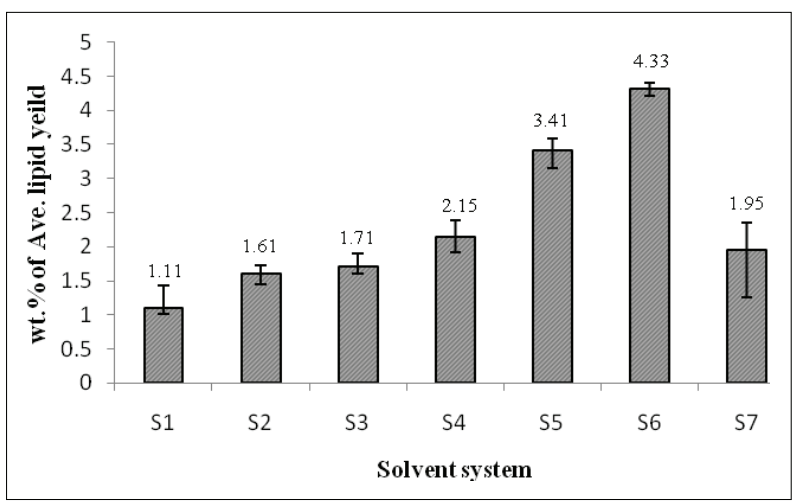

Figure 1: Percentages of average lipid yields (wt. \% of lipid $\mathrm{g} / 1 \mathrm{~g}$ dried biomass). Error bars represent the minimum and maximum of the data set.

S1 - n-hexane; S2 - chloroform: methanol (2:1); S3 n-hexane: ethanol (3:2); S4 - chloroform: n-hexane (1:1); S5 - DCM: methanol (1:1); S6 - n-hexane: isopropanol (2:3); S7 - diethyl ether.

The total lipid composition of microalgae and cyanobacteria vary with many parameters, such as the species, environment conditions, nutrient availability and phase of life cycle, etc; especially in logarithmic growth phase they have higher lipid contents than the same species, which are in stationary phase (Dunstan et al., 1993).

Griffiths and Harrison (2009) reported that the lipid content of cyanobacteria was about $5-13$ wt. \% with an average of 8 wt. \%. The highest lipid yields from Chlorella sp.(11.9 wt. \%), Isochrysis galbana (8.9 wt. \%), Botryococcus braunii (28.6 wt. \%), Phaeodactylum 
tricornutum (6.3\%) and Chlorococcum sp. (6.8\%) were recorded in other countries as well (Guckert et al., 1988; Grima et al., 1994; Fajardo et al., 2007; Lee et al., 2010; Halim et al., 2011). In the present study, it was found that lipid yields of Microcystis spp. varied from $1.1 \mathrm{wt}$. \% to $4.33 \mathrm{wt}$. \%. The lipid yield of the present study was relatively lower than the recorded values for other algae. Most of the researches on biodiesel production from microalgae has been carried out under controlled systems while in the present study, Microcystis bloom samples were collected from Beira Lake, which is subjected to different environmental variations such as light, temperature, $\mathrm{pH}$, carbon dioxide and nutrient content (Manage, 2009; Idroos et al., 2014). Further Da Rós et al. (2012) recorded that cell growth, biomass productivity and lipid content of microalgae depend on some important factors such as light, temperature, $\mathrm{pH}$, carbon dioxide and nutrient concentration. Therefore, this could be one of the reasons which influence the reduction of lipid yield in the present study.

Table 1: Volume of FAME products related with different solvent systems

\begin{tabular}{lccccccc}
\hline Solvent system & S1 & S2 & S3 & S4 & S5 & S6 & S7 \\
\hline $\begin{array}{l}\text { Produced FAME volume } \\
\text { (mean vol. } \pm \text { SD) }(\mathrm{mL})\end{array}$ & $2.73 \pm 1.08$ & $6.20 \pm 0.36$ & $7.10 \pm 0.40$ & $20.20 \pm 1.7$ & $6.97 \pm 0.80$ & $13.56 \pm 0.21$ & $1.5 \pm 0.80$ \\
\hline
\end{tabular}

As shown in Table 1 the highest FAME volume $20.20 \pm 1.7 \mathrm{~mL}$ was obtained from S4 where $\mathrm{n}$ - hexane: chloroform (1:1) solvent system was used. The lowest volume $1.5 \pm 0.80 \mathrm{~mL}$ was recorded from $\mathrm{S} 7$ solvent system where di-ethyl ether was used as the solvent. The final volumes [means $(\mathrm{mL}) \pm \mathrm{SD}$ ] of FAME products of $\mathrm{S} 1, \mathrm{~S} 2, \mathrm{~S} 3, \mathrm{~S} 5$ and S6 solvent systems were detected as $2.73 \pm 1.08,6.20 \pm 0.36,7.10 \pm 0.40,6.97 \pm 0.80$ and $13.56 \pm 0.21$, respectively.

Twelve types of methyl esters were detected by GCMS screening from all solvent systems. They were identified as dodecanoic acid methyl ester (C13:0), tridecanoic acid methyl ester (C14:0), pentadecanoic acid 14-methyl methyl ester (C17:0), hexadecanoic acid methyl ester (C17:0), 7-hexadecenoic acid methyl ester (C17:1), 7, 10, 13- hexadecatrienoic acid methyl ester (C17:3), octadecanoic acid methyl ester (C19:0), 7-octadecenoic acid methyl ester (C19:1), 13-octadecenoic acid methyl ester (C19:1),15-octadecenoic acid methyl ester (C19:1), 9,12 - octadecadienoic acid methyl ester (C19:2) and 11,14- eicosadienoic acid methyl ester (C21:2) (Xu et al., 2006; Da Rós et al., 2012).

Out of the detected FAMEs, hexadecanoic acid methyl ester and pentadecanoic acid 14-methyl methyl ester were the major FAME products (Figure 2). Under threshold value 14, the highest FAME percentage was recorded as $92.39 \%$ from the solvent system 6 , where the n-hexane: isopropanol (2:3) system was used for lipid extraction, and total FAMEs were expressed as hexadecanoic acid methyl esters. The second highest percentage $(85.72 \%)$ was recorded from the S5 solvent system where dichloromethane: methanol (1:1) was used for lipid extraction and the most abundant FAMEs were pentadecanoic acid 14-methyl methyl esters. Further, relatively higher FAME percentages of the solvent systems $\mathrm{S} 1, \mathrm{~S} 2, \mathrm{~S} 3$ and $\mathrm{S} 7$ were recorded as $80.13 \%, 78.27 \%, 76.39 \%$ and $80.09 \%$, respectively (Figure 2). The lowest FAME percentage (29.01 \%) was recorded from $\mathrm{S} 4$ solvent system when n-hexane: chloroform (1:1) was used for lipid extraction and the recorded FAME type was hexadecanoic acid methyl ester (Figure 2).

FAME components of tridecanoic acid methyl esters (1.59\%), 7-hexadecanoic acid methyl esters (1.54\%), octadecanoic acid methyl esters (3.59\%), 7- octadecanoic acid methyl esters (5.42\%), 13- octadecanoic acid methyl esters $(2.5 \%)$, 15- octadecanoic acid methyl esters $(2.62 \%)$ and 9,12- octadecadienoic acid methyl esters $(4.99 \%)$ were detected in S1 solvent system as minor components. In S2 solvent system, octadecanoic acid methyl esters $(7.67 \%)$ and 11,14 - eicosadienoic acid methyl esters were detected. Dodecanoic acid methyl esters, 7, 10, 13- octadecatrienoic acid methyl esters and octadecanoic acid methyl esters were recorded in S7 at $0.19 \%, 7.68 \%$ and $7.08 \%$, respectively as minor components (Figure 2).

Many experiments on mixed-solvents (polar and nonpolar solvent mixture) have given higher lipid extraction than the other tested solvent systems. Most of the polar lipids were assumed to be the major contaminant in the extracted lipids, which cause some problems in esterification process (Halim et al., 2011) and utilising of biodiesel. 

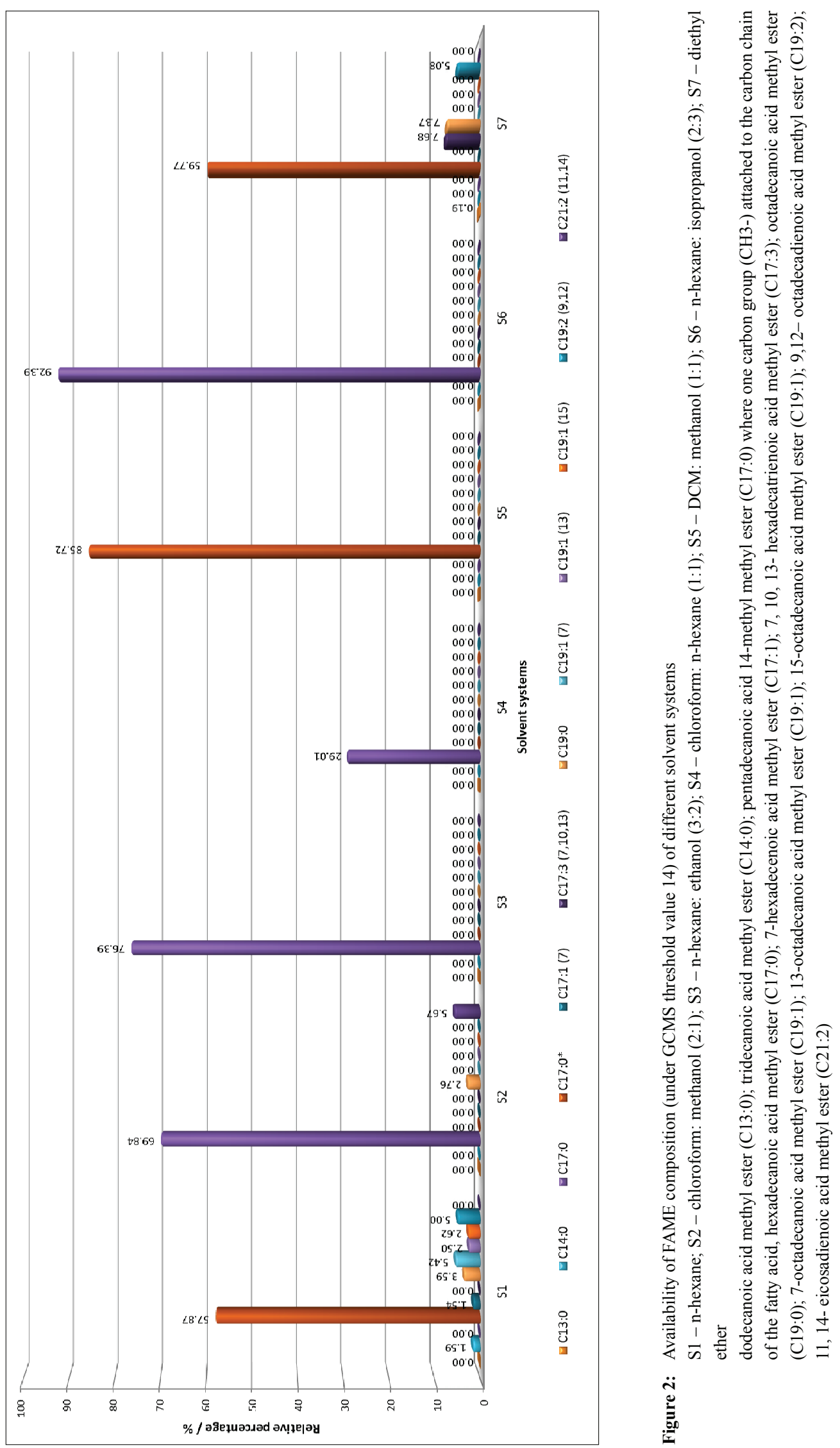

تِّ 
According to Da Rós et al. (2012) major saturated fatty acids of Microcystis was palmitic acid (C16:0) and lauric acid (C12:0), and such acids were recorded as $24.34 \%$ and $13.21 \%$, respectively and myristic acid (C14:0) was recorded as low as $6 \%$. The predominant unsaturated fatty acids were oleic acid (C18:1) and linoleic acid (C18:2), which represented $26.88 \%$ and $12.53 \%$, respectively. However, erucic acid (C22:1), linolenic acid (C18:3) and palmitoleic acid (C16:1) were detected in low percentage up to $3 \%$.

The trans-esterified products of S3, S4, S5 and S6 in which lipids were extracted from $\mathrm{n}$-hexane: ethanol (3:2), n-hexane: chloroform (1:1), DCM: methanol (1:1) and n-hexane: isopropanol (2:3) systems, respectively, resulted only saturated FAMEs (100 \%). When S1 solvent system was used with n-hexane solvent system $78.68 \%$ of saturated FAMEs, $15.08 \%$ of monounsaturated FAMEs and $6.23 \%$ of poly-unsaturated FAMEs were obtained. The lipid products obtained from chloroform: methanol (2:1) solvent mixture (S2) had $92.76 \%$ of saturated FAMEs and others were polyunsaturated FAMEs that were available as $7.24 \%$ from the total FAMEs. In S7 solvent system, $84.07 \%$ from the total FAMEs were saturated and other $15.93 \%$ of FAMEs were poly-unsaturated (Table 2).

Results of the present study revealed that the saturated and unsaturated FAME composition was more or less similar to that recorded by Da Rós et al. (2012).

Table 2: Saturated and unsaturated FAME compositions of solvent systems

\begin{tabular}{|c|c|c|c|c|}
\hline \multirow[b]{3}{*}{ Solvent system } & \multicolumn{4}{|c|}{ Percentage from total FAME* } \\
\hline & \multirow[b]{2}{*}{ Total FAME $\% *$} & \multirow{2}{*}{$\begin{array}{c}\text { Saturated } \\
\text { FAME }\end{array}$} & \multicolumn{2}{|c|}{ Unsaturated FAME } \\
\hline & & & Mono-unsaturated & Poly-unsaturated \\
\hline S1 & 80.13 & 78.68 & 15.08 & 6.23 \\
\hline S2 & 78.27 & 92.76 & ND & 7.24 \\
\hline $\mathrm{S} 3$ & 76.39 & 100.00 & ND & ND \\
\hline S4 & 29.01 & 100.00 & ND & ND \\
\hline S5 & 85.72 & 100.00 & ND & ND \\
\hline S6 & 92.39 & 100.00 & ND & ND \\
\hline S7 & 80.09 & 84.07 & ND & 15.93 \\
\hline \multicolumn{5}{|c|}{ * - FAME screening carried out under GCMS threshold value 14} \\
\hline \multicolumn{5}{|c|}{$\mathrm{ND}-$ not detected } \\
\hline $\begin{array}{l}\text { S1 - n-hexane; } S \\
(1: 1) ; \text { S5 - DCN }\end{array}$ & $\begin{array}{l}\text { chloroform: meth } \\
\text { ethanol (1:1); S6 }\end{array}$ & $\begin{array}{l}2: 1) ; S 3-n \\
x a n e: \text { isop }\end{array}$ & $\begin{array}{l}\text { Ine: ethanol (3:2); S4 } \\
\text { ol (1:1); S7 - diethy }\end{array}$ & $\begin{array}{l}\text { loroform: n-hexane } \\
\text { r }\end{array}$ \\
\hline
\end{tabular}

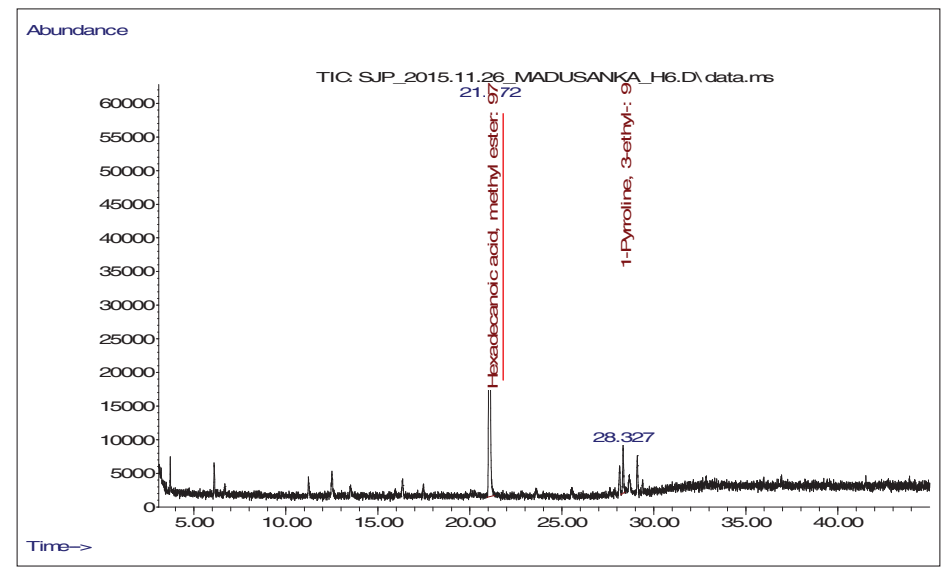

Figure 3: GC-MS for S6 solvent system which used n-hexane: isopropanol (2:3) for lipid extraction 


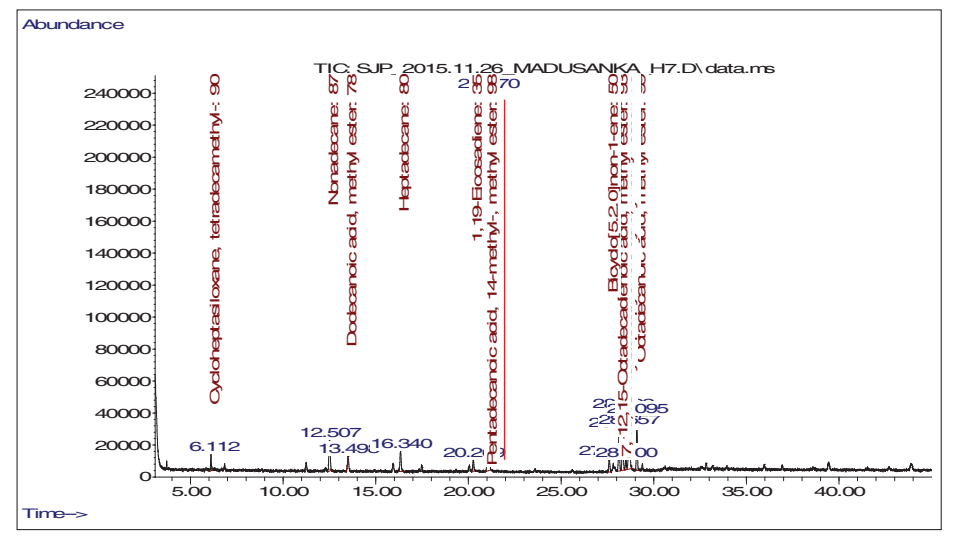

Figure 4: GC-MS for S7 solvent system which used diethyl ether for lipid extraction

The dominant saturated FAME types of Microcystis were methyl esters of palmitic acid and its derivatives (hexadecanoic acid methyl esters and pentadecanoic acid 14-methyl methyl esters). Both hexadecanoic acid methyl esters and pentadecanoic acid 14-methyl methyl esters have seventeen carbon atoms and thirty-four hydrogen atoms. Therefore, both compounds have the same molecular weight (Figures 3 and 4).

Although these FAMEs have some characters in common, they vary in their chain length, carbon atom and hydrogen atom arrangements. Pentadecanoic acid 14-methyl methyl ester has a methyl group on the fourteenth carbon atom in the hydrocarbon chain. Therefore, hexadecanoic acid methyl ester hydrocarbon chain length is higher than pentadecanoic acid 14-methyl methyl ester. Thus, the most abundant FAME type in S1, S5 and S7 solvent systems were found to be pentadecanoic acid 14-methyl methyl esters. It was found that hexadecanoic acid methyl ester was abundant in S2, S3, S4 and S6 solvent systems.

In the present study, pure non-polar solvents such as n-hexane and diethyl ether were used in S1 and S7 systems, respectively. Other five solvent systems were mixed solvent systems and among these, S2, S3, S5 and S6 consisted of polar/non-polar solvent mixtures, which contained chloroform: methanol (2:1), n-hexane: ethanol (3:2), DCM: methanol (1:1) and n-hexane: isopropanol (2:3), respectively. S4 solvent system contained a mixture of two non-polar solvents; chloroform: n-hexane (1:1). For optimising a solvent system for lipid extraction, lipid yield of each solvent system, FAME composition, availability of co-extractions, and other physical and chemical parameters were considered.
It is significant that higher FAME compositions result in higher volumes of biodiesel. A higher FAME composition is a key requirement to a quality biodiesel product. Figure 5 shows the mean FAME volumes and FAME percentages of the solvent systems. The circled areas represent the mean volumes, which were obtained from each solvent system. S1, S2, S3, S5, S6 and $\mathrm{S} 7$ achieved high FAME percentages (under GCMS threshold value 14), while S4 recorded a relatively low FAME percentage. Relatively high volumes were recorded from S4 and S6 while S7 solvent system had a low FAME yield. Although, S4 solvent system has a high FAME mean volume, it showed the lowest FAME percentage. S6 solvent system showed a relatively high FAME volume while achieving the highest FAME percentage from all solvent systems.

Lipid extractability (the lipid solubility within a particular solvent system) depends on the total energy of cohesion between lipid molecule and solvent system divided into three major components; atomic dispersion (van der Waals) interactions, molecular dipolar interactions and molecular hydrogen bonding (electron exchange) interactions. As pointed out by Halim et al. (2012), n-hexane:isopropanol solvent system has a lower relative energy difference (RED) according to Hansen solubility parameters.

Use of non-polar solvents mixed with polar solvents increased the lipid extractability from cyanobacteria, and n-hexane:isopropanol mixture was highly selective for neutral lipids because they are not able to extract polar lipids such as glycolipids in chloroplasts and phospholipids in cell membrane, which ensured the selectivity for neutral lipids (Guckert et al., 1988). In the present study, 
it was observed that the n-hexane:isopropanol solvent system was the most efficient solvent system to extract lipids from Microcystis spp.

Extraction pretreatments are very important to remove water content of the biomass. According to Mubarak et al. (2014), moisture content more than $5 \%$ in biomass reduce the oil extraction yield and increase the free fatty acid fraction of oil. Therefore, the Microcystis biomass was dried under solar light to reduce the water content and it also reduced energy consumption for the process. Although minimum operational cost was beneficial, time consumption and resulting higher free fatty acids (FFA) (Balasubramanian et al., 2013) in biomass were the major drawbacks of this technique.

According to literature, lipid extraction from Chlorococcum sp. was enhanced with the inclusion of isopropanol as a co-solvent, which resulted in increasing the total lipid yield of pure n-hexane system by more than $300 \%$ [total lipid yield of pure n-hexane system was $0.015 \mathrm{~g} / \mathrm{g}$ dried microalgal biomass and final total lipid yield of n-hexane:isopropanol $(1 / 1 \mathrm{v} / \mathrm{v})$ system was $0.068 \mathrm{~g}$ lipid/g dried microalgal biomass] (Halim et al. 2011). Similarly, in the present study, the total lipid yield obtained from pure n-hexane system was $0.011 \mathrm{~g} / \mathrm{g}$ from dried Microcystis biomass, while total lipid yield from n-hexane:ethanol $(1 / 1 \mathrm{v} / \mathrm{v})$ and $\mathrm{n}$-hexane:isopropanol $(2 / 3 \mathrm{v} / \mathrm{v})$ were 0.017 and $0.043 \mathrm{~g}$ lipid/g dried microalgal biomass, respectively. Thus, the present study revealed that the inclusion of ethanol and isopropanol as co-

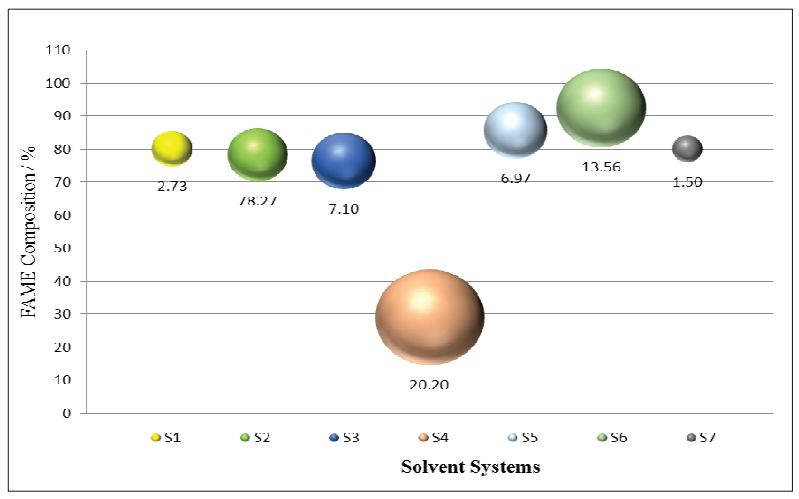

Figure 5: Comparison of FAME composition and volume of final product of each solvent system.

S1, S2, S3, S4, S5, S6 and S7 are solvent systems where $\mathrm{S} 1$ - n-hexane; S2 - chloroform: methanol (2:1); S3 n-hexane: ethanol (3:2); S4 - chloroform: n-hexane (1:1); S5 - DCM: methanol (1:1); S6 - n-hexane: isopropanol (1:1); S7 - diethyl ether. (The area of circle represents the mean volume) solvents improves the total lipid yield of pure n-hexane system by more than $150 \%$ and $350 \%$, respectively. Further, it was found that mixture of non-polar solvents (n- hexane:chloroform) resulted in the lowest FAME percentage following the highest volume, indicating the presence of co-extractions.

\section{CONCLUSION}

Out of seven solvent systems, n-hexane: isopropanol solvent system showed high selectivity to extract neutral lipids and could obtain $92 \%$. Genus Microcystis mostly consists of palmitic acid (hexadecanoic acid) or its derivatives (pentadecanoic acid 14-methyl). Inclusion of polar solvents with non-polar solvents increases the extractability of lipids from the Microcystis biomass. The results of the present study revealed that Microcystis bloom can be used to produce biodiesel as an alternative energy source.

\section{REFERENCES}

1. Balasubramanian R.K., Doan T.T.Y. \& Obbard J.P. (2013). Factors affecting cellular lipid extraction from marine microalgae. Chemical Engineering Journal 215: 929 - 936. DOI: https://doi.org/10.1016/j.cej.2012.11.063

2. Brennan L. \& Owende P. (2010). Biofuels from microalgae - a review of technologies for production, processing, and extractions of biofuels and co-products. Renewable and Sustainable Energy Reviews 14(2): 557 - 577. DOI: https://doi.org/10.1016/j.rser.2009.10.009

3. Chisti Y. (2007). Biodiesel from microalgae. Biotechnology Advances 25(3): 294 - 306.

DOI: https://doi.org/10.1016/j.biotechadv.2007.02.001

4. Da Rós P.C.M., Silva C.S.P., Silva-Stenico M.E., Fiore M.F. \& de Castro H.F. (2012). Microcystis aeruginosa lipids as feedstock for biodiesel synthesis by enzymatic route. Journal of Molecular Catalysis B: Enzymatic 84: $177-182$.

DOI: https://doi.org/10.1016/j.molcatb.2012.04.007

5. Daroch M., Geng S. \& Wang G. (2013). Recent advances in liquid biofuel production from algal feedstocks. Applied Energy 102: 1371 - 1381.

DOI: https://doi.org/10.1016/j.apenergy.2012.07.031

6. Dunstan G.A., Volkman J.K., Barrett S.M. \& Garland C.D. (1993). Changes in the lipid composition and maximisation of the polyunsaturated fatty acid content of three microalgae grown in mass culture. Journal of Applied Phycology 5(1): $71-83$.

DOI: https://doi.org/10.1007/BF02182424

7. Fajardo A.R., Cerdan L.E., Medina A.R., Fernández F.G.A., Moreno P.A.G. \& Grima E.M. (2007). Lipid extraction from the microalga Phaeodactylumtri cornutum. European Journal of Lipid Science and Technology 109(2): 120 - 126. DOI: https://doi.org/10.1002/ejlt.200600216 
8. Griffiths M.J. \& Harrison S.T. (2009). Lipid productivity as a key characteristic for choosing algal species for biodiesel production. Journal of Applied Phycology 21(5): 493 - 507. DOI: https://doi.org/10.1007/s10811-008-9392-7

9. Grima E.M., Medina A.R., Giménez A.G., Pérez J.S., Camacho F.G. \& Sánchez J.L.G. (1994). Comparison between extraction of lipids and fatty acids from microalgal biomass. Journal of the American Oil Chemists' Society 71(9): 955 - 959 .

DOI: https://doi.org/10.1007/BF02542261

10. Guckert J.B., Cooksey K.E. \& Jackson L.L. (1988). Lipid solvent systems are not equivalent for analysis of lipid classes in the micro eukaryotic green alga, Chlorella. Journal of Microbiological Methods 8(3): 139 - 149.

11. Guschina I.A. \& Harwood J.L. (2006). Lipids and lipid metabolism in eukaryotic algae. Progress in Lipid Research 45(2): $160-186$.

DOI: https://doi.org/10.1016/j.plipres.2006.01.001

12. Halim R., Daquan M.K. \& Webley P.A. (2012). Extraction of oil from microalgae for biodiesel production: a review. Biotechnology Advances 30(3): 709 - 732.

DOI: https://doi.org/10.1016/j.biotechadv.2012.01.001

13. Halim R., Gladman B., Danquah M.K. \& Webley P.A. (2011). Oil extraction from microalgae for biodiesel production. Bioresource Technology 102(1): 178 - 185. DOI: https://doi.org/10.1016/j.biortech.2010.06.136

14. Huang D., Zhou H. \& Lin L. (2012). Biodiesel: an alternative to conventional fuel. Energy Procedia 16: 1874 -1885 .

DOI: https://doi.org/10.1016/j.egypro.2012.01.287

15. Huang G., Chen F., Wei D., Zhang X. \& Chen G. (2010). Biodiesel production by microalgal biotechnology. Applied Energy 87(1): 38 - 46. DOI: https://doi.org/10.1016/j.apenergy.2009.06.016

16. Idroos S.F., Hettiarachchi I.U.C. \& Manage P.M. (2014). Seasonal variation of microcystin-LR with respect to some physico-chemical parameters in the Beira Lake waters. Proceedings of International Conference on Multidisciplinary Approaches 1(2): 27 - 37.

17. Lee J.Y., Yoo C., Jun S.Y., Ahn C.Y. \& Oh H.M. (2010). Comparison of several methods for effective lipid extraction from microalgae. Bioresource Technology 101(1): 75 - 77. DOI: https://doi.org/10.1016/j.biortech.2009.03.058

18. Manage P.M. (2009). Seasonal changes in the abundance of biological agents killing Microcystis aeruginosa in a hypereutrophic pond. Vidyodaya Journal of Science 14(2): $85-101$.

19. Metzger P. \& Largeau C. (2005). Botryococcus braunii: a rich source for hydrocarbons and related ether lipids. Applied Microbiology and Biotechnology 66(5): 486 - 496. DOI: https://doi.org/10.1007/s00253-004-1779-z

20. Miao X. \& Wu Q. (2006). Biodiesel production from heterotrophic microalgal oil. Bioresource Technology 97(6): $841-846$.

DOI: https://doi.org/10.1016/j.biortech.2005.04.008

21. Moser B.R. (2009). Biodiesel properties and feedstocks. Society for In-Vitro Biology 45(3): 229 - 266.

22. Mubarak M., Shaija A. \& Suchithra T.V. (2014). A review on the extraction of lipid from microalgae for biodiesel production. Algal Research 7: 117 - 123. DOI: https://doi.org/10.1016/j.algal.2014.10.008

23. Sethunga S. \& Manage P.M. (2013). Nuisance algae in water supply projects in Sri Lanka. International Conference on Sustainable Built Environment (ICSBE-2010), Kandy, Sri Lanka, 13 - 14 December, pp. $62-70$.

24. Shafiee S. \& Topal E. (2008). When will fossil fuel reserves be diminished? Energy Policy 37(1): 181 - 189. DOI: https://doi.org/10.1016/j.enpol.2008.08.016

25. Xu H., Miao X. \& Wu Q. (2006). High quality biodiesel production from a microalga Chlorella protothecoides by heterotrophic growth in fermenters. Journal of Biotechnology 126(4): 499 - 507.

DOI: https://doi.org/10.1016/j.jbiotec.2006.05.002 